\title{
Tracing the ELF: Joyful Excursions in Search of Evolution
}

\author{
Emanuele Serrelli
}

Published online: 13 October 2009

(C) Springer Science + Business Media, LLC 2009

Keywords Bibliography · Manual · Textbook · Evolution . Education $\cdot$ Teacher materials

The Joy of Science: An Examination of How Scientists Ask and Answer Questions Using the Story of Evolution as a Paradigm, by Richard A. Lockshin. Dordrecht, The Netherlands: Springer, 2007. Pp. xi $+435 . \mathrm{H} / \mathrm{b} \$ 99.00$.

I once won a fellowship with an essay that began to answer the question, 'How did you become interested in science?' with the statement, 'All children are biologists. Some of us never outgrow it.'

Richard Lockshin, 2008

The Joy of Science is the kind of title which arouses your curiosity. If you learn something about the author, curiosity will increase.

Richard A. Lockshin is a leading scientist in the study of cell death. Such a field contributes not only to the understanding and control of diseases (cancer, degenerative diseases, infection, and many others) but also to the comprehension of the fundamental role of "constructive death" in the functioning of organisms. In 1964, Lockshin introduced no less than the term "programmed cell death" (PCD), recognizing new proteins synthesized during the process and launching the pioneering idea that PCD — executed through a series of catabolic reactions from inside the self-destroying

\footnotetext{
E. Serrelli $(\bowtie)$

"Riccardo Massa" Department of Human Sciences, University of Milan Bicocca,

Piazza dell'Ateneo Nuovo, 1, 20126 Milan, Italy

e-mail: emanuele.serrelli@unimib.it

e-mail: emanuele.serrelli@epistemologia.eu
}

cell — would be triggered and controlled by a combination of cell-extrinsic and cell-intrinsic factors. Collaborating with several individuals, Lockshin went on to do more groundbreaking researche: for example, he was among the first to study the physiology of dying cells and to question why they shrank, to recognize that the regulation of oncogenes was important in cell death, and to emphasize the multiplicity of kinds of death processes (see, e.g., Zakeri 2008).

So what to expect from a book entitled The Joy of Science from an outstanding molecular biologist? When you look through the book, you clearly recognize a textbook style: Chapters are monographic units; they are short (with some exceptions) and closed by series of "study questions." You understand that the manual's main topic is biological evolution, but the logical order and span of arguments seem unusual in respect to other textbooks; much space is devoted to historical reconstruction-but Darwin's name appears less than you would expect from a history of evolutionary biology; topics in geology and social history occupy a relevant part of the book; molecular biology appears as late as in Part 4 (p. 189), whereas evolution textbooks usually introduce it as the first and primary issue; then, if you remember that Lockshin is a molecular biologist, you may feel puzzled if you look at Part 5 (p. 243), where the history of Earth and the origin of life take place, followed by the origin of species and the evolution of humans. If you run through the book's illustrations, you will get the impression of a collection of disparate images: Many are photos of animals and plants from the Internet; others are original drawings - curious intuitive schemes rather than the rigorous illustrations commonly found in scientific manuals and articles.

If you ask who the book is written for and what use is it intended for, you will have to search a bit. Yet if you look 
for a declaration about its general goals, that you will easily find. If the aim of such an edition was to arouse intellectual curiosity, it is reached, and what you will find will not disappoint you: Pieces will find place, and you will actually have a taste of The Joy of Science.

\section{The ELF of Science}

The point cannot be made too strongly: The logic of science, and the structure of science, is simply human logic. It requires the same skills that we use on a daily basis, and is no more complex than that (p. 8).

A main goal of Richard Lockshin's book-written, as we read in the preface, "for those who do not intend to major in sciences"- is to convince the reader that "the logic and construction of scientific thinking" is something humans have used in everyday life from time immemorial-long before the birth of modern science. A central message Lockshin wants to convey is that everyone can experience the joy of science since "it ain't rocket science," i.e., it is understandable, and everyone has to understand in order to achieve the "informed citizenry" which is necessary to live in our society.

The book's challenging task is to present scientific topics (from evolutionary biology in particular) in a way that makes the structure of science obvious, and the first step is to outline a synthetic description of how science works: ELF, that is, evidence, logic, and falsification. Honoring Lockshin's idea that ELF is best understood through examples from the history of science, you will find hints on some of his better stories in the next paragraph. Meanwhile, another element must be added to this core: curiosity. In presenting Darwin, Lockshin will write: "All children are curious. Many of those who do not lose that curiosity become scientists" (p. 87), and further on, in introducing the roots of his own field of study, he will use the following metaphor:

Science is an onion. It consists of questions, but each answer opens a new question, much as an onion consists of layer after layer of modified leaves. It is not unusual for a scientist to publish hundreds of papers over a lifetime, yet with each paper insist that he or she is working on the same problem-just delving deeper and deeper into the problem, peeling another layer off the onion. It is much the same issue as realizing the many layers of what seems to be a simple question that a child might ask (p. 191).

But the everyday use of ELF and curiosity are not sufficient to cover science as a whole. Lockshin writes in fact about some peculiarities of science: mathematics: necessary for detailed analysis, precision, and prediction; vocabulary: technical terms are a fundamental element of science, since scientific language strives for a precision that "assures that any worker through the world, on seeing a specific word, will have the same mental image" (p. 9). That is why "we will not attempt to 'talk down' to you, the student, by using less mature, less specific vocabulary. We will, however, in introducing a less common word attempt to explain it in passing" (p. 15); abstractness: science deals with abstraction, because often its object is not part of common experience, but "the ability to think abstractly is the ability to make the abstract concrete" (p. 12); and figures, graphs, and tables, which "summarize important points, indicate relationships, and suggest further expansion of an idea" (p. 12).

The aspects of science that differentiate it from everyday thinking, Lockshin admits, can bring some difficulty. Nonetheless, science can be explained and deeply understood, as the author hopes to show in his presentation of evolution.

\section{The Best ELF Stories}

Let us examine some of Lockshin's examples, to see his idea that science consists of a continuous flow among evidence, logic, and falsification. It seems that scientific stories can begin from any of the three.

Evidence (either obtained by observation or experiment) suggests a possible link between two phenomena. By the mid-nineteenth century, various sources of evidence had accumulated which pointed to the relatedness between species, their common descent, and patterns of modification. However, such evidence constituted nothing more than a bunch of anomalies opposing the view of living beings based on Scriptures, until Charles Darwin (and A.R. Wallace) did provide the logic behind that, i.e., the mechanism of natural selection. In older times, the logic supplied by early geologists like Nicholas Steno, Louis Agassiz, and Charles Lyell provided a framework in which to explain known evidence of similarities and connections between different areas of our planet, of patterns of distribution in geological strata, of the presence of seashells on the mountain tops, or of stones resembling shark's teeth on the island of Malta. To be considered as such, evidence needs logic.

A developed logic can be used to search for (further) evidence. One of the more exciting and well-told stories of the book is Who killed the dinosaurs? The Chicxulub Detective Story (Chapter 28). It was triggered when Walter and Luis Alvarez in 1973 gave shape to the (logic) hypothesis of an asteroid impact 65 million years ago. As in a police story, Lockshin narrates the exciting search for 
multiple independent sources of evidence converging not only on the probable existence but also on the particular site of the impact. The hypothesis is today the more widely (although not unanimously) accepted explanation for the K-T extinction.

Evidence cannot prove logic once and for all, nor can it establish causality. Rather, scientists can manage to exclude competing hypotheses by setting up experiments and predictions. That is, seeking falsification. Lockshin's book is rich in examples from the history of medicine. In the mid-seventeenth century, Francisco Redi tested the spontaneous generation of maggots against his alternative hypothesis of egg deposition by flies. Testing several kinds of meat in several conditions, repeating the experiment, and setting up a control experiment ("all other things being equal"), he was able to absolutely exclude spontaneous generation, opening ground for subsequent work by Pasteur, Koch, and Snow. Similarly, smart experiments have been done in the twentieth century when the task was to identify whether DNA or proteins were carriers of genetic information. Falsification can end up providing either new corroborating evidence for the accepted logic or a pool of open problems for future explanations. Research is being conducted to seek refutation (or corroboration?) of the asteroid Chicxulub hypothesis, while the theory of evolution and the Darwinian logic of natural selection are being confirmed by more and more pieces of evidence.

\section{ELF in Context: Science is a Historical Enterprise}

As we already noted, in The Joy of Science, evolutionary biology appears surrounded and mixed with a range of scientific and social arguments. In Chapter 2, for example, you find that the invention of the telescope in the seventeenth century must be placed in the context of the prize money offered by the king of Spain to solve a particular problem:

ship captains knew how to calculate latitude (distance north or south of the equator) by the height of the sun at noon-again a practical result of the mechanistic approach to the philosophy of what the world wasbut they could not calculate longitude, the distance east or west of their home base (p. 25).

In a similar way, the birth of geology has to be linked with the need to predict the presence of valuable minerals and to organize mining operations, whereas the increased medical study of details and practical aspects of life was fostered by new concerns of kings and queens about government and protection. In The Joy of Science, scientists are introduced in their historical context. In this way, Lockshin succeeds in outlining fascinating pictures of what appears to be an enterprise of humanity - or, better, of the Western world.

Also at the sociohistorical scale, Lockshin's effort to describe the ELF structure is evident. Moreover, at the very birth of modern science, Lockshin presents a circular dynamics in which science's success in addressing specific problems validates the assumption that "much could be learned by the physical world," leading to further inquiries and success. Science - a new, peculiar form of ELF-was the best means to solve problems, and this allowed natural philosophers (later called scientists) to gain ascendancy over theologians and philosophers.

But what about evolutionary biology? Which problem(s) was it aimed to solve? Lockshin's account makes very clear the relatedness of biology to the age of exploration as well as to the identification of the principles of geology. In the sixteenth and seventeenth centuries, growing evidence concerning the geographical distribution, number, and boundaries of species brought forth many problems with the logic of the biblical account of Creation and the Great Flood. Species were found confined in places that did not fit well in the logic of a distribution by Noah's Ark (Chapter 4). Furthermore:

...in a limited territory such as an island, species were quite distinct and easily discriminated. It was only when a zoologist ranged over larger territories and found geographical variation [...] that it become difficult to tell where, in terms of shape and color, one species ended and another began (p. 47).

Scientific efforts to systematize the whole living worldsuch as those by Linnaeus - revealed to be never ending and unconclusive, leading to put in debate their own fundamental concepts (“does a species really exist? Do genera really exist?", Chapter 5). Through these stories, Lockshin takes us into a world characterized by loss of certainty (similar growth of concerns are found in physics, geology, cartography) and open problems, even though with a didactical intention - he jumps ahead to our days to briefly explain our concepts of species and higher taxa (Chapter 6, interesting tables and figures here).

Since before its birth as a science, geology consorted with the study of the history of life. When Lockshin narrates how Nicholas Steno (1638-1686) came to generalize his principles - sort of laws - on how mountains are built, hillsides and other geological formations are produced, valleys are excavated, and so on (Chapter 3), we learn the initial question of the whole story:

There are fossils, unequivocally of marine animals, near the tops of the mountains. Why are there? (p. 37).

So when we encounter Darwin (as late as in Chapter 7), we are plunged in the views and problems of his epoch, as 
well as the ideas, solutions found, and problems encountered by the ELFs before him. Chapter 7 is about The Voyage of the Beagle. Quoting here and there from Darwin's landmark book, it narrates something about where Darwin explored, what did he saw and thought. Especially, what his training was and which phenomena caused him to doubt: mainly, geological forces and the sense of time they conveyed (Darwin made calculations about the formation time of mountain ranges, obtaining results of the order of hundreds thousands years) and the idiosyncratic distribution of animals throughout the world (he noticed, for example, similar but distinct species of flightless birds with puzzling nonoverlapping ranges or several unique species in small archipelagos which are similar to the nearest continental species). At the end of Chapter 7, we are left with just a hint of Darwin's reading Malthus, natural selection and simultaneity with Wallace ("an excellent example of the ELF rule" according to Lockshin), and the social context in which their remarkable story developed, only to get backin the subsequent chapter - to the question "Is the Earth old enough for evolution?"

The importance of geology in evolution can hardly be overestimated, and we will get back on it in paragraph 5 . Here, note Lockshin's idea of science as a means for solving problems that are left open and ingrained in the needs of the society in a historical moment.

The necessity of logic may not be apparent either to scientists or to the public until other information becomes available. Often, the interest in a question is driven by new findings or by new social concerns (p. 148).

Chapter 12, Darwin's hypothesis, presents Darwin's explanation as the best available, linking all known "weirdnesses" of the living world in a simple way, whichin accomplishment with Occam's Razor (another element of scientific logic) - prevailed over others.

\section{Multiple Streams Flowing into Ideas}

In the nineteenth century and in particular with Darwin, Western society acquired a vision of the world where the age of the Earth was unimaginably extended from thousands to billions of years; the living world was seen in constant change rather than in an eternal and perfect order; there was room for evolution ("or, more properly, natural selection"); and science showed not only all its power but also its truest structure.

As Lockshin explores the previous worldview (e.g., Chapter 2), we are faced with Aristotle, Plato, and Biblical Genesis, but there is no illusion of an easy, clear-cut barrier between old and new. The reader appreciates, for example, that physics and an attitude toward physical laws originated in Greek scholarship (e.g., Archimedes, or Aristotle himself), coming later to Europe via Spain through the contact between Islamic and Jewish philosophers such as Maimonides. Ideas about geological processes were already known by, e.g., a mystical sect of Shiite Muslims, "The Brothers of Purity," as well as by the Uzbeki/Persian physician Avicenna (980-1037 A.D.). Presenting ideas as always tracing back to predecessors (individual and social problems and solutions) helps the reader to avoid viewing history as a sequence of watertight "periods."

Similarly, "many of the main elements of the story of evolution were well known long before 1859" (p. 23). For example, Georges Cuvier (1769-1832) and Etienne Geoffroy Saint-Hilaire (1772-1844) had already understood in the late eighteenth and early nineteenth centuries, studying anatomy and fossils, that "the stratification of fossils told the history of animal and plant life" and that creatures "had changed over time, with some types of animals completely disappearing," but they lacked a conception of the time that it took, and a new, grand theory of mechanism (the logic). Naturalist J.B. Lamarck (1744-1829), embryologist K.E. von Baer (1792-1876), anatomist Richard Owen (1804-1892), and many others contributed with their ELF work to the still-to-come theory of evolution.

In Chapter 10, Lockshin addresses the work by English economist Thomas Malthus (1766-1834), whose essential point was that "populations increase exponentially, while resources increase linearly" (p. 152), such dynamics resulting in a "struggle for existence." Much discussed among Victorian intellectuals, "that great philosopher" Malthus was read both by Darwin and Wallace. Here, is another example of the fact that

...ideas come from many sources, including social concerns to which scientists as well as others are susceptible (p. 154).

Darwin was a genius for his recognition of the fact that "variations are the heart of the story" rather than an annoyance, as well as for his ability to make connections among apparently disparate ideas. Struggle for existence is, for Lockshin, just "the first half of Darwin's hypothesis":

The second part of the insight was that who would live and who would die would not necessarily be completely random (p. 157).

Then The Joy of Science explains the logic of natural selection in a careful and dry fashion. In Darwin's idea, variation itself is not random, but is - at least in partinherited, and the survival and spread of some varieties is not random, since such varieties slightly favor their bearers. 


\section{Life and the Earth: the Multidisciplinary Span of Evolution}

The Joy of Science moves in long-period oscillations between Earth and life sciences. One important story is about Louis Agassiz (1807-1873, Chapter 6) and his discovery of deep similarities between the Alps and American mountains, with particular regard to glaciers and glacial orogenesis. There was abundant biological evidence of an Ice Age (e.g., fossils of animals and plants with characteristic features, tree rings...), and in turn, the possibility of the existence of massive glaciers carried several implications for the history of life, none of which were compatible with the Biblical description:

We can assume that the same demands are placed on all animals and plants. Thus the fact that the climate of the earth has fluctuated strongly means that species have been pushed from one location to another and that they have frequently been under severe stress, which perhaps forced them to change (p. 78).

Then, just after narrating Darwin's voyage and sketching out his intuitions, the book presents the parallel history of the measurement of the age of the Earth (Chapter 8), from Lord Kelvin's calculations to the discovery of radioactive heating and radiodecay, up to today's availability of multiple independent means of assessment (which all converge on 4.5 billion years for the Earth, and six billion years for the universe). In fact, although "one of the most important passages in Voyage of the Beagle" is Darwin's exploration in the Andes Mountains, followed by his calculation of their age, a problem was left open: calibration. There were principles by Nicholas Steno, Lyell, and others. Principles enable us to answer questions such as: what do I expect to find and where? How do I have to interpret what I see and what I find? But "there was no means of calibrating clocks based on sedimentation or erosion" (p. 104) or other geological process. In other words, it was possible to answer the question about "which processes in which order" but not "how much time did it take."

Part 5, The history of the Earth and the origin of life, brings together all evidence telling us which steps could have led to the origin of life as we know it:

... at present we cannot assemble the entire story.

Based on evidence and logic, we can hypothesize several of the steps that probably occurred (p. 245).

The topic comes after some chapters on how life works at the molecular level (see next paragraph here), and this provokes the clear sensation that the larger scale scenario and the molecular scale are in need of each other for a complete understanding. Lockshin presents the peculiar chemical properties of carbon and water, making them the best candidate elements to be the base for life - and limiting its existence, for example, to a certain range of temperatures; experiments about the conditions prevailing in early Earth; multiple traces of the presence of life (most of them pointing to around 3.5 billion years ago); the astonishingly late explosion of diversity 500 million years ago; the possible atmospherical and biochemical causes of these transitions, the lag period in between, and the importance of oxygen in this story; and the symbiogenetic origin of eukaryotes and the origin of multicellularity. In Lockshin's favorite interpretation, the Cambian explosion was due to atmospheric accessibility of land to life. But, always coherent with his ELF, Lockshin admits:

There are other possible explanations, including the development of specific types of genes. There are no "correct" explanations for the Cambrian explosion; interpretations that we have are speculations based on the evidence that we have and logical interpretations of the evidence, but there is no criterion of falsifiability to solidify the hypothesis into a theory (p. 278).

An account follows of The great ages of our planet (Chapter 20), in which Lockshin runs from Precambrian to Cenozoic, describing fossil traces and organisms found in sediments of different ages, together with interesting notes about the origin of names of the eras - most of which date back to the seventeenth and eighteenth centuries (when, of course, they still lacked time depth and evolutionary interpretation). The fascinating story of the return of mammals to water (Cetacea, Chapter 21) describes one of the more recent and particular branches of the evolutionary bush of life.

Chapters 22-23 are dedicated to The violence of Earth, that is the colossal phenomena of change that radically modify conditions of life, displace species and populations, and trigger mass extinctions. Some space is devoted to the history of the discovery of continental drift and of its unexpected speed ("continents were connected in biological time!"):

The violence of the Earth is very similar to that of a traffic accident, in this instance one of a light-weight car colliding with a more massive one [...]. They will crumple, and the lighter one will go above the top of the heavier one. This is what happens when the expanding sea floor plows into the side of a continent (p. 313).

Continental drift finally explained some of the bizarre distributions of animals and plants, being today corroborated by new studies and discoveries. Related phenomena like rain shadows and volcanoes have an extremely deep impact on species' life, evolution, and extinction. 
It may seem remarkable to find a molecular biologist so sensitive to ecological, biogeographical, and geological instances in explaining evolution. These are the sort of factors usually privileged by other professionals, namely paleontologists. One of the most distinguished supporters of their importance is Niles Eldredge, whose "general prediction about evolution" is the following:

...most evolution - and certainly the appearance of most new species, must lie somewhere between local ecosystem degradation, on one hand, and global mass extinction on the other-with its proportionately great effects on the histories - extinction and evolution - of larger ("higher") taxa (Eldredge 2008, p. 14).

\section{A Matter of Cool Tricks}

The central part of the book is devoted to the author's working field: molecular biology. Here, The Joy of Science realizes its maximum effectiveness. Chapter 13 recounts how the first studies on inheritance (between the nineteenth and twentieth centuries) challenged Darwinian evolutionary theory and how "1900 was somewhat a turning point for the acceptance of the theory of evolution" (p. 188). The problem of dilution, for instance, was solved by embryologist August Weissmann's discovery of the physical separation between somatic and germ cells-which allows for transmission of hidden characteristics that reappear uncorrupted in subsequent generations. The establishment of Mendelian genetics allowed for quantitative studies of inheritance in populations.

In Chapter 14, Lockshin uniquely combines historical analysis with principles of molecular biology, so that every principle — still used today - is presented as a "really cool trick," conceived in a particular moment of history, and since then conserved in molecular biologists' toolkit.

This is the story of the rise of molecular biology, surely one of the great episodes in the history of science $[. .$.$] . For the most parts, asking the question$ and getting an answer was a matter of games and tricks. In the vernacular, "Molecular biology ain't rocket science". It mostly is a matter of cool tricks (p. 192).

To give an idea of the content and style of the chapter, which is really worth reading, we listed the "cool tricks" in Table 1. For example, cool tricks \#1 and \#2 tell how Avery et al. (1943) and Hershey and Chase (1952) came to give evidence of the fact that DNA is the genetic material, not proteins. Cool trick \#3 is the story of how Watson-Crick and others got the double-helix structure. Cool tricks \#5 and \#6 explain how we arrived at getting viruses to cut DNA for us, then separating and studying the cut sequences. Common feature of all these "tricks" was their aim to make observable something unobservable.

The excursion in molecular biology is really effective in showing the importance of a deep comprehension of entities and processes that make sense of evolution:

To understand what evolution is, what selection is, and how it works, we need to look at the physical mechanism by which it occurs (p. 221).

It not only means dealing with genetic "information" but also with the organic context, with chemical processes, products, and pathways inside organisms:

...to understand what evolution is, in a sense somewhat more complete that "rabbits are brown to hide from their enemies", we need to have a sense of the components of evolution. In other words, we need to know what makes rabbits brown, and how evolution can create white and brown rabbits (p. 221).

It is clear that genetic "information" and related metaphors like "universal algorithms" and so on are often an idealization of genetics by those who are not geneticists. Proteins, carbohydrates, fats, DNA, mRNA, and tRNA, the mechanisms of transcription and translation, are the next stars in Lockshin's explication (Chapter 15), always
Table 1 The list of "really cool tricks" of molecular biology described in Chapter 14 of The Joy of Science

The history of molecular biology is presented as a series of smart solutions to problems of observing and modifying organic molecules in a pursuit of the question "What is the basis of inheritance?"
"Really cool tricks" in molecular biology

\#1 How to turn a not-so-bad bug into a really bad one

\#2 Bacterial milkshakes

\#3 Molecular billiards and Russian dolls

\#4 Playing in the kitchen is wonderful for babies and future Nobel laureates

\#5 Viruses know how to cut up DNA

\#6 Getting DNA to race

\#7 Looking for crazy bacteria

\#8 If the water main is working at First St. but not at 3rd St., then the blockage must be near 2nd st. \#9 When all the puzzle pieces are the same 
enriched by vivid accounts of discoveries and discoverers. One of the most interesting remarks here is the universality of the genetic code (i.e., the constant correspondence between triplets and amino acids-terms we can now understand thanks to Lockshin's plain explanations). Universality is remarkable because slightly modified codes are physically possible and functionally equivalent. So:

Basically, the fact that the code is universal would be the equivalent of Europeans arriving in the New World, stepping off the boat, and realizing that the Arawak and Carib Indians addressed them in perfect Spanish! [...] This is the strongest argument we have that all life came from one original living type (p. 232).

Lockshin comes then to illustrate another element of evolutionary conservatism: the frequency of conserved genes such as those codifying for caspases, eye development, and homeotic genes - the latter responsible for establishing the basic layout of the body - all shared in incredible varieties of organisms. Survival of genes indicates both the importance of the genes and common descentwhich can be reconstructed by tracing back gene lineages connecting the more diverse forms.

\section{Just the Logic of Evolution}

Chapter 11 is all about the logic and inference underlying "natural selection" and "survival of the fittest," two terms that "cause considerable confusion (and anger) whenever evolution is discussed [because they] are often used in public in a sense broader that, or even in conflict with, the scientific meaning" (p. 158). Again, the point is, for Lockshin, that:

scientific terminology is by necessity precise, while ordinary speech is not (Ibidem).

And it is just the marvelous logic of natural selection that makes it a bricoleur, arranging the better solution possible with "available stuff," a process by which we are not allowed to expect perfection, optimality, or cruel elimination of whatever is imperfect:

The rule is that, whatever works, works. Any adaptation that improves the possibility of leaving progeny can be selected for (p. 161).

And a perfectly reasonable corollary is:

If it ain't broke, don't fix it (p. 165).

Such a logic elegantly explains phenomena like evolutionary stasis in some species (sometimes wrongly described as perfection of adaptation) or vestigial organs, unused but preserved in evolutionary history.
In a paragraph entitled "Punctuated equilibrium" (Chapter 12), Lockshin enumerates some contemporary debates in evolutionary theory (relative importance of sexual selection, kinds of speciation processes, levels of selection, rhythms, and rates of evolution), pointing out that:

Scientists, and especially biologists and geologists, do not "disagree about the theory of evolution" (p. 172).

There is only one theory of evolution, and it is fully Darwinian.

There is essentially no doubt that evolution has occurred. The theory of natural selection is the best-and extremely well substantiated-hypothesis describing the mechanism by which varieties that we see today were created. What is in discussion today is the details of the mechanism (p. 173).

So the reader is informed about the theoretical framework in which he has to place the subsequent chapters, beginning from The crisis in evolution (Chapter 13) and Part 4, The molecular basis of evolutionary theory, whichas we have seen - can be considered the technical core of the book and one of the main revolutions in life sciences after Darwin.

Part 6, The Origin of Species, briefly reviews some evolutionary mechanisms which are part of the contemporary theory of evolution. Competition for biological niches, founder effect, allopatric and sympatric speciation, can be summarized by the following quotation:

The general principle is that, if a species can specialize to avoid competition with other species, it has the potential of surviving. The alternative is too horrible to contemplate. The mechanics of adaptation to apparently dreadful conditions is escape from annihilating competition (p. 340).

Explanation of the variety of life - including lifestyles, habits, and habitats which are the most bizarre to our eyes - comes not only from ecological competition but also from sexual selection (Chapter 25) and coevolution under its many appearances - such as mutualism, parasitism, and mimicry (Chapter 26). An interesting evolutionary link is found between the latter three phenomena:

...it is generally considered that the most virulent disease-causing organisms are those that have only recently begun to attack their hosts. Many organisms that cause severe disease in one host produce mild or no symptoms in other hosts. In these cases it can often be demonstrated by DNA sequencing that the host with the mildest form of the disease is the original host [...] both parasite 
and host evolve toward a less noxious form of interaction (p. 358).

Disease (Chapter 27) can exert strong selective pressures, create bottlenecks, and therefore be a source of important evolutionary novelties. As an evolutionary force, it can be at the origin no less than sexual reproduction itself:

...the function of sex, and the reason that most animals and plants invest enormous energy in sex, is the limitation of disease (p. 366).

Chapter 28 in one more well-written ELF story about the iatrogenic hypothesis for AIDS (i.e., the hypothesis that AIDS was introduced to humans through vaccination against polio) and the eventual scientific (so, open to new researches) refutation of the hypothesis.

Part 7 recounts what we know today about the evolution of humans - this part is really not much updated, but researches in this field are in constant movement so that any book grows old fast (see the recent Tattersall 2008; Wood 2006). It is the story of a bush of species rooted four million years ago (although tightly related with the 60 million-year-long story of primates). Here you can find a description of relevant differences and common traits between species belonging to genera Australopithecus and Homo, the always exciting story of our multiple ventures out of Africa, as well as genetic and phenotypic connections and variations among modern humans and between them and living primates. An attention to ELFthat is "how we know what we think we know"-is present in this final part of the book too. Chapter 30, under the title of When did humans acquire a soul? tackles the relationship between religions and science. Lockshin makes some reflections on the issues, but his position can be expressed in few words, put as a paragraph title:

Science cannot prove or disprove Scripture, and Scripture cannot prove or disprove scientific hypothesis (p. 403).

Supposed incompatibilities derive, for Lockshin, from fundamentalist positions which characterize periods or groups within the various religions.

\section{Logics and Statistics}

Chapter 9, Evaluating Data, opens Part 3 (Origin of the Theory of Evolution: Social Aspects). Here Lockshin summarizes some important concepts about contemporary natural sciences championed by evolutionary biology. When experiments cannot be conducted, falsification can be sought through the formulation of "risky predictions," or else through corroborating evidence, that is the accumulation of "many independent lines of evidence that point out to the same conclusion" (p. 113), making scientific research similar to forensic police stories. With some telling examples from medicine, plain figures, and tables, Lockshin brings the reader to understand that statistics provide powerful tools for detecting correlations and also for corroborating hypotheses and discarding fragile ones:

A baby born in December gets larger as the weather grows warmer. We cannot conclude however that the temperature causes the baby to grow, and in fact the correlation will deteriorate as autumn comes (p. 123).

Correlations like this one can be vulnerable to the passage of time and the widening of the considered population; others can be highly applicable, but in any case - unlike widespread misinterpretations-statistics cannot prove causality.

Going on, Lockshin explains the technical meaning of "significance":

To a scientist, the word "significant" has one meaning only: "unlikely to occur by chance alone more than five times out of 100" (p. 126).

Other terms like "normal distributions," "clustering," "control experiment," "causality," and more like these are explained in a straightforward and simple way, completing the chapter with an exciting, exemplary narration of the rise of microbiology via the scientific adventures of von Leeuwenhoek, Redi, Pasteur, Harvey, Koch, and Snow.

Chapters 31 and 32 are an extensive treatment of the impact that evolutionary theory-like any scientific theory - can have on society and politics, especially in cases where an interest exists in discriminating individuals or entire groups. Chapter 31 tells the history of eugenics and the IQ test, tracing back to Linnaeus' classificatory confrontation with the human kind, coming up to Alfred Binet and de Gobineau in France, to H.H. Goddard in USA, and to Cyril Burt and Francis Galton in England, with many original quotations (this part is inspired by the work of Stephen Jay Gould (1981), who together with Jared Diamond (1997) is among the main inspiring sources for the whole book). Reading this story:

It might all sound laughable, but it led to two of the worst laws in American history as well as to the rise of Nazism in Europe (p. 422).

Lockshin conducts an analysis of the flaws present in those "scientific studies" rooted in wrong interpretation of statistics and confusion between correlation and causality. Since these are still today the most common mistakes in the comprehension of science and since scientists are humans 
and operate within the assumptions of the society ("science is never totally politically neutral"), for Lockshin, it all leads to the ethical responsibility of citizens, "those who are not doing science": They are in charge of both understanding science and remembering the social imperatives, resisting the impulse - which is always possible - of making or asking for bad law in the name of science. The Joy of Science closes, then, with the plea:

Hopefully you, the citizenry, will be sufficiently wellinformed to understand the importance of evidence, logic, and falsification, and you will evaluate the data, and make moral and compassionate decisions on that basis. If you can do this, then we as scientists have succeeded our mission (p. 434).

\section{Comments}

The Joy of Science is a textbook on evolution, but you can read it from the beginning to the end and enjoy.

As a textbook, it presents a somewhat atypical order and span of topics. In sum, the book is particularly effective in presenting evolution together with geology and Earth sciences in an inseparable continuum; in showing mechanisms underlying science that are common to different disciplines and historical moments; yet in making manifest the importance of the historical context shaping and directing scientific research; and in emphasizing a degree of continuity in science, following the confluence-in scientific explanation - of previous ideas, across boundaries between "periods." In the preface, the author suggests to using "this book for a one-semester or two-semester course," possibly in the setting of small classes in which discussion is encouraged. He does not define age groupshe probably wrote for university students, but we may also hypothesize some uses in high school. In any case, as we already reported, the book is intended "for those who do not intend to major in sciences." Each chapter ends with a series of good "essay style" questions to be used in consolidating learning. An index helps in locating particular arguments in the book. Illustrations, as we pointed out, are for the main part images from the Internet; then, there are many nice, rough, and intuitive schemes; few graphs or technical images. We connect this to the particular characteristics of the book and to its relationship to teaching.

Whatever the use of this book in teaching will be, it is clear that it is a product of many teaching experiences by the author. We can appreciate his method made of excursionslike, for instance, the one exploring the elaboration of the principles of geology, or the other diving into the preenlightenment views of nature. Teaching excursions consist in going inside problems, trying to gather information (for example, from the Internet) in a problem-solving attitude which is proper to science. We find confirmation of it in a quotation from the preface:

I have found it useful in my teaching to allow the curiosity of students to redefine the directions I take, and the book reflects some of these directions. It is not necessary to address evolution through an excursion into molecular biology [sic!], but molecular biology is relevant, interesting, and currently in the headlines. I therefore have included excursions such as these into the text, but I highly encourage teachers and others planning a course to omit these excursions, as they see fit, or to use them as supplementary materials.

If you take a look at the references at the end of chapters, you will see the same: some good books and many Internet resources. By the way, "The Joy of Science" is also a channel on Youtube (http://www.youtube.com), and Richard Lockshin is a main proponent of a project of scientific exchange with the "Third World" and other countries (http://scientistswithoutfrontiers.org/). Lockshin, a scientist, prefers to explore new territories with his students, and even when he comes to his own field (molecular biology), he seems less concerned with defending notions than with presenting them with the pleasure of discovery. If you will, consider Lockshin's book an interesting example of teaching style - one that can make students feel The Joy of Science.

Lockshin's clearly stated epistemological thesis is that "science is an ELF," that is a continuous movement between evidence, logic, and falsification. To the author, such a movement is very similar to what we all do in everyday life, although in science you have mathematics, technical vocabulary, a high level of abstraction, and particular ways of representation, making it a more powerful means of discovery. The Joy of Science raises the challenge to present each and every scientific argument in a way that makes the ELF structure clear. In this respect, the book succeeds: It is highly readable and gives you the pleasure (Joy!) of understanding. Reading the episodes, you have a rich picture of the scientific enterprise, with its continuity between open problems and smart ways ("cool tricks") to solve them, as well as the interplay between individual work, cooperation, and the needs of society.

It must be said that the three components of ELF are not given equal attention throughout the book. For example, just in the chapters devoted to contemporary evolutionary biology, you find a presentation of the logic of speciation, sexual selection, etc. but without real attention to evidence that can be found in nature for those mechanisms or to falsification that potentially excludes other explanations. Maybe to an extent it is a matter of space. In the chapters 
about molecular biology and geology, you find the three elements, and scientific change is seen as a dynamic between them (see paragraph 2 above).

Some remarks can be made about ELF itself. From an epistemological, philosophical point of view, Lockshin's analysis of science appears quite simplistic. It relies on Popperian falsificationism. Of course, Karl Popper is an exceedingly important reference in the philosophy of science, but his analyses have been criticized throughout the twentieth century. His view of science, although stimulating and overcoming theoretical obstacles of previous descriptions, is seen as highly idealized and "normative" (i.e., it is about what scientist "should do" and not what they actually do). Let it be sufficient to cite Thomas Kuhn's idea of "enduring paradigms," where in periods of normal science scientists are not willing to falsify and abandon their fundamental idea, the paradigm they are working in; or Imre Lakatos, for whom "research programmes" are capable of defending their core principles by means of a protective belt of auxiliary assumptions exposed to falsification. Also the existence and unity of the scientific method (pp. ix, 4) have been questioned - and is in question to date - and there would be many other important issues such as progress (are new theories always better than previous ones? How can I confront them? Is science an improvement in respect to less refined forms of reasoning?), realism (how much dies reality depend on the observer?), and the possibility of setting up true falsifying experiments (for an introduction to these issues, see Okasha 2002). And even if you limit yourself to Lockshin's narrations, you can see that ELF is not enough to define science.

Accordingly, you may note an excess of optimism when Richard Lockshin states that:

You apply the logic of science (hopefully) every day in your life. A local fast-food chain offers a huge icecream sundae that contains "only five calories"; you wonder if that's true (what the evidence is; how logically can it be sweet without sugar). One mild day in winter, a friend remarks that the mildness is due to global warming; it crosses your mind that last week was a record low temperature. On television, an ad touts a "miracle brush" that can remove spilled dry paint with a single swipe; you are very skeptical and look very closely at the ad to judge if what is being shown actually happened [...]. Even a decision whether or not to walk to the next bus stop rather that wait, or to take a taxi rather than wait for the bus, is based on a hypothesis about the time on the route and your fatigue or energy (pp. 7-8).

To prejudiced ears, all these may sound like examples in which normally ELF is absolutely not used. Maybe a similar bias can be recognized in Lockshin's effort to describe scientific research as a series ELF cycles?

Given this, Richard Lockshin's endeavor to present scientific explanations as problem solving in their historical context is very interesting and realized in The Joy of Science. The ELF structure-frequently recalled through the chapters - appears to be didactically effective. Above all, certainly all of us can share the goal of the book: "demystifying the world of science" (p. 14), making it understandable and accessible to everybody, because understanding is the basis of an informed and conscientious citizenry and because it can give you pleasure and joy.

\section{References}

Avery O.T., MacLeod C.M., McCarthy M. Studies on the chemical nature of the substance inducing transformation of pneumococcal types. Inductions of transformation by a desoxyribonucleic acid fraction isolated from pneumococcus type III. J Exp Med. 1944; 149:297-326.

Diamond J. Guns, germs, and steel: The fates of human societies. New York: W.W. Norton \& Co.; 1997.

Eldredge N. Hierarchies and the sloshing bucket: toward the unification of evolutionary biology. Evo Edu Outreach. 2008; $1: 10-5$.

Gould S.J. The mismeasure of man. New York: W.W. Norton \& Co; 1981.

Hershey A.D., Chase M. Independent functions of viral protein and nucleic acid in growth of bacteriophage. J Gen Physiol. 1952; 36:39-56.

Okasha S. Philosophy of science: a very short introduction. Oxford: Oxford University Press; 2002.

Tattersall I. The world from beginnings to 4000 BCE. Oxford: Oxford University Press; 2008.

Wood B. Human evolution: a very short introduction. Oxford: Oxford University Press; 2006.

Zakeri Z. Honoring contributions of Richard A. Lockshin to the field of cell death. Cell Death Differ. 2008;15(7):1087-8. 